\title{
Prevalence trends in respiratory symptoms and asthma in relation to smoking - two cross-sectional studies ten years apart among adults in northern Sweden
}

Helena Backman ${ }^{1,2^{*}}$, Linnea Hedman ${ }^{1}$, Sven-Arne Jansson ${ }^{1,2}$, Anne Lindberg ${ }^{1,3}$, Bo Lundbäck ${ }^{1,4}$ and Eva Rönmark ${ }^{1,2}$

\begin{abstract}
Background: Smoking is considered to be the single most important preventable risk factor for respiratory symptoms. Estimating prevalence of respiratory symptoms is important since they most often precede a diagnosis of an obstructive airway disease, which places a major burden on the society. The aim of this study was to estimate prevalence trends of respiratory symptoms and asthma among Swedish adults, in relation to smoking habits. A further aim was to estimate the proportion of respiratory symptom and asthma prevalence attributable to smoking.

Methods: Data from two large-scale cross-sectional surveys among adults performed in northern Sweden in 1996 and 2006 were analysed. Identical methods and the same questionnaire were used in both surveys. The association between smoking, respiratory symptoms and asthma was analysed with multiple logistic regression analyses. Changes in prevalence of respiratory symptoms and asthma from 1996 to 2006 were expressed as odds ratios. Additionally, the population attributable risks of smoking were estimated.

Results: The prevalence of most respiratory symptoms decreased significantly from 1996 to 2006. Longstanding cough decreased from 12.4 to $10.1 \%$, sputum production from 19.0 to $15.0 \%$, chronic productive cough from 7.3 to $6.2 \%$, and recurrent wheeze from 13.4 to $12.0 \%$. Any wheeze and asthmatic wheeze remained unchanged. This parallels to a decrease in smoking from 27.4 to 19.1\%. In contrast, physician-diagnosed asthma increased from 9.4 to $11.6 \%$. The patterns were similar after correction for confounders. All respiratory symptoms were highly associated with smoking, and the proportion of respiratory symptoms in the population attributed to smoking (PAR) ranged from 9.8 to $25.5 \%$. In 2006, PAR of smoking was highest for recurrent wheeze (20.6\%).

Conclusions: In conclusion, we found that respiratory symptoms, in particular symptoms common in bronchitis, decreased among adults in northern Sweden, parallel to a decrease in smoking from 1996 to 2006. In contrast, the prevalence of physician-diagnosed asthma increased during the same time-period. Up to one fourth of the respiratory symptom prevalence in the population was attributable to smoking.
\end{abstract}

Keywords: Respiratory symptoms, Asthma, Prevalence, Smoking, Attributable risk, Trends

\footnotetext{
* Correspondence: helena.backman@nll.se

${ }^{1}$ The OLIN Studies, Department of Research and Development, Norrbotten

County Council, Luleå, Sweden

${ }^{2}$ Division for Occupational and Environmental Medicine, Department of

Public Health and Clinical Medicine, Umeå University, Umeå, Sweden

Full list of author information is available at the end of the article
} 


\section{Background}

Tobacco consumption is one of the main risk factors of premature death and disability worldwide [1]. The use of tobacco is rising globally mainly because of an increasing smoking prevalence in many low and middle income countries [2]. The societal costs of diseases related to tobacco use are substantial; e.g. estimated to more than $€ 500$ billion in 2009, which corresponds to $4.6 \%$ of the Gross Domestic Product of the European Union [3]. In 2008 , about one out of three adults in the world smoked [4], and the overall pattern in the World Health Organisation (WHO) European region was similar. In Sweden however, the prevalence of smoking has decreased during the last decades $[5,6]$.

Smoking is considered to be the single most important preventable risk factor for respiratory symptoms, chronic bronchitis and chronic obstructive pulmonary disease (COPD) [7]. The relationship between asthma and smoking is unclear, and contradictory results have been found in different studies. Smoking has been considered a risk factor for incident asthma in some studies [8-10], while others have found no association [11]. Some cross-sectional studies on asthma prevalence have found an association between ex-smoking or ever-smoking and asthma [6,12], while others have found no such association [13,14].

Asthma, chronic bronchitis and COPD contribute a major burden on the society in terms of disability, mortality and costs [15-17]. The prevalence of asthma has been increasing from the 1950s [18-21], however, recent studies imply that the asthma increase might have reached a plateau in several westernized countries $[6,22,23]$. Worldwide, the burden of COPD is steadily increasing [24]. Estimating prevalence of respiratory symptoms is important since symptoms most often precede a diagnosis of an obstructive airway disease [7], and since symptom prevalence less likely is biased by healthcare practice or diagnostic activity compared to diagnoses of obstructive airway diseases. Few recent studies among adults have reported trends in prevalence of respiratory symptoms and asthma.

Within the Obstructive Lung Disease in Northern Sweden (OLIN) Studies, prevalence and incidence of obstructive airway diseases have been studied since 1985 [25]. The aim of the present study was to estimate prevalence trends of respiratory symptoms and asthma among adults in relation to smoking habits by two large-scale cross-sectional studies performed in 1996 and 2006. A further aim was to estimate the proportion of respiratory symptom and asthma prevalence attributable to smoking.

\section{Methods}

\section{Study population}

This study was performed in Norrbotten, the northernmost county of Sweden. In 1996, a population-based sample of 8,333 subjects in ages 20-69 years were sent a postal questionnaire including questions about respiratory symptoms, diseases and smoking habits. The sample was randomly selected from the Swedish population register. After two reminders, 85\% participated.

Correspondingly, a new random sample consisting of 7,997 subjects in ages 20-69 years were invited in 2006. The methodology and questionnaire were identical with the 1996 survey and 77\% participated (Table 1). The total population in Norrbotten between 20-69 years of age was approximately 168,000 in 1996 and 159,000 in 2006.

\section{Questionnaire}

The questionnaire includes questions on respiratory symptoms and diseases, demographic data, smoking and other possible determinants of disease. It was developed from the British Medical Research Council questionnaire and has been used in several large-scale studies mainly in Sweden, Finland and Estonia [6,9,22,25-28].

\section{Definitions}

\section{Asthma variables}

Physician-diagnosed asthma: Have you been diagnosed as having asthma by a physician. Ever asthma: Do you have, or have you ever had asthma. Asthma medication: Do you use asthma medication (on a regular basis or when needed).

\section{Bronchitis variables}

Longstanding cough: Have you had longstanding cough during recent years. Sputum production: Do you usually have phlegm when coughing, or do you have phlegm in your chest that is difficult to bring up. Chronic productive cough: Bringing up phlegm when coughing on most days during periods of at least 3 months during at least 2 successive years.

\section{Wheeze variables}

Any wheeze: Have you at any time during the last 12 months had wheezing or whistling in your chest. Recurrent wheeze: Do you usually have wheezing or whistling in your chest when breathing. Asthmatic wheeze: Wheeze with breathlessness during the last 12 months when you did not have a cold.

\section{Other variables}

Family history of asthma: Does any of your parents or siblings have, or have had, asthma. Smokers reported smoking during the 12 months preceding the survey, while Ex-smokers reported having quit smoking at least 12 months prior to the study. Smokers answered a question about the number of consumed cigarettes: $<5$ cigarettes per day, 5-14 cigarettes per day, or $>14$ 
Table 1 Study population, invited and participants by study year, age group and sex

\begin{tabular}{|c|c|c|c|c|c|c|c|c|c|}
\hline & & \multicolumn{5}{|c|}{ Age group } & \multicolumn{2}{|c|}{ Sex } & \multirow[b]{2}{*}{ All } \\
\hline & & $20-29 y$ & $30-39 y$ & $40-49 y$ & $50-59 y$ & $60-69 y$ & Women & Men & \\
\hline \multicolumn{10}{|c|}{ Study year 1996} \\
\hline Invited & $N$ & 1619 & 1721 & 1895 & 1694 & 1404 & 3982 & 4351 & 8333 \\
\hline \multirow[t]{2}{*}{ Participated } & $n$ & 1317 & 1429 & 1616 & 1490 & 1252 & 3471 & 3633 & 7104 \\
\hline & $\%$ & 81.3 & 83.0 & 85.3 & 88.0 & 89.2 & 87.2 & 83.5 & 85.3 \\
\hline \multicolumn{10}{|c|}{ Study year 2006} \\
\hline Invited & $\mathrm{N}$ & 1428 & 1514 & 1718 & 1820 & 1517 & 3843 & 4154 & 7997 \\
\hline \multirow[t]{2}{*}{ Participated } & $n$ & 941 & 1080 & 1312 & 1510 & 1322 & 3135 & 3030 & 6165 \\
\hline & $\%$ & 65.9 & 71.3 & 76.4 & 83.0 & 87.1 & 81.6 & 72.9 & 77.1 \\
\hline
\end{tabular}

cigarettes per day. Non-smokers reported neither smoking nor ex-smoking.

\section{Ethical approval}

The study was approved by the Regional Ethical Review Board at Umeå University, Sweden.

\section{Analysis}

Statistical analyses were performed using the IBM SPSS software (Version 20.0; SPSS Inc., Chicago IL, USA). Differences in prevalence between groups were tested by the chi-square test or Mantel-Haenszel test for trend and differences in continuous variables were tested by a two-tailed Student's T-test. A p-value $<0.05$ was considered statistically significant. Multiple logistic regression models were used in order to calculate Odds Ratios (OR:s) with 95\% confidence intervals (CI) for the simultaneous effects of independent variables on different outcomes. The independent variables in the logistic regression models were; age, sex, smoking habits, family history of asthma and year of study, where age was divided into 10year categories. The same model was also applied for each study year separately (each survey).

The population attributable risk (PAR) in\% of a certain risk factor expresses the proportion of the prevalence of a condition in the population which is attributable to that risk factor. PAR of smoking was calculated each year as: $\left(\left(\mathrm{P}_{\mathrm{T}}-\mathrm{P}_{0}\right) / \mathrm{P}_{\mathrm{T}}\right) * 100$, where $\mathrm{P}_{\mathrm{T}}=$ Prevalence of $\mathrm{a}$ symptom/disease among all and $\mathrm{P}_{0}=$ Prevalence of a symptom/disease among non- and ex-smokers. Corresponding 95\% CI for PAR were calculated using the Maximum Likelihood method [29].

PAR was also calculated based on Odds Ratios for smoking (non- and ex-smoking as reference) from logistic regression models adjusted for age, sex and family history of asthma, and is then referred to as "adjusted PAR". The formula for adjusted PAR is as follows: ((OR1)/OR) $* \mathrm{P}^{*} 100$, where $\mathrm{P}=$ Prevalence of smoking among cases with the symptom/disease [30].

\section{Results}

\section{Participation}

The participation rate was significantly higher in 1996 compared to 2006 in most age groups and among men and women. In 1996, 7,104 adults (85\%) participated and in 2006, 6,165 (77\%) participated. In both surveys, the participation rates were higher among women compared to men, and increased by age (Table 1 ).

\section{Smoking habits}

The prevalence of smoking decreased significantly from $27.4 \%$ in 1996 to $19.1 \%$ in 2006 ( $<<0.001$ ). The decrease was significant in all age groups as well as among men and women (Table 2). Additionally, the proportion of smokers who smoked $>14$ cigarettes/day decreased among both smoking women (from 21.5 to $17.9 \%, \mathrm{p}=0.073$ ) and men (from 35.2 to $26.0 \%, \mathrm{p}=0.001$ ).

Smoking habits differed significantly $(\mathrm{p}<0.001)$ between age groups in both surveys, with smoking being most common among subjects 40-59 year old (Table 2 ). In both surveys, more women than men were smokers $(\mathrm{p}<0.001)$.

\section{Respiratory symptoms and asthma}

The prevalence of most respiratory symptoms decreased significantly from 1996 to 2006. Longstanding cough decreased from 12.4 to $10.1 \%$, sputum production from 19.0 to $15.0 \%$, chronic productive cough from 7.3 to $6.2 \%$ and recurrent wheeze from 13.4 to $12.0 \%$. Any wheeze and asthmatic wheeze remained unchanged. In contrast, the prevalence of ever asthma increased significantly from 10.1 to $13.4 \%$, physician-diagnosed asthma from 9.4 to $11.6 \%$ and the use of asthma medication from 10.9 to $12.4 \%$ (Table 3 ). The change in prevalence from 1996 to 2006 expressed as odds ratios is displayed in Figure 1. A significant decrease was found for longstanding cough (OR 0.82, 95\% 0.74-0.92), sputum production (OR 0.80, 95\% 0.72-0.87) and chronic productive cough (OR 0.85, 95\% 0.74-0.98), while physiciandiagnosed asthma increased (OR 1.28, 95\% 1.14-1.44). 
Table 2 Prevalence (\%) of smoking habits by study year, age group and sex

\begin{tabular}{|c|c|c|c|c|c|c|c|c|c|c|}
\hline & \multirow[b]{2}{*}{ n All } & \multicolumn{5}{|c|}{ Age group } & \multicolumn{2}{|c|}{ Sex } & \multirow[b]{2}{*}{ All } & \multirow[b]{2}{*}{ All $^{\mathrm{D}}$} \\
\hline & & $20-29 y$ & $30-39 y$ & $40-49 y$ & $50-59 y$ & $\overline{60-69 y}$ & Women & Men & & \\
\hline \multicolumn{11}{|c|}{ Smoking habits 1996} \\
\hline Non-smokers & 3600 & 69.3 & 55.0 & 41.3 & 42.0 & 50.8 & 51.9 & 50.3 & 51.1 & 51.5 \\
\hline Ex-smokers & 1511 & 9.3 & 17.9 & 24.9 & 26.5 & 27.8 & 18.6 & 24.1 & 21.5 & 21.1 \\
\hline Smokers & 1932 & 21.4 & 27.1 & 33.7 & 31.5 & 21.3 & 29.4 & 25.5 & 27.4 & 27.4 \\
\hline$<5$ cig/day & 402 & 7.3 & 7.0 & 5.9 & 5.0 & 3.3 & 5.1 & 6.3 & 5.7 & 5.8 \\
\hline 5-14 cig/day & 944 & 10.5 & 13.0 & 17.0 & 15.1 & 10.4 & 17.3 & 9.7 & 13.4 & 13.4 \\
\hline$>14$ cig/day & 523 & 2.9 & 6.3 & 10.2 & 10.4 & 6.4 & 6.1 & 8.7 & 7.4 & 7.3 \\
\hline Missing data & 63 & 0.8 & 0.8 & 0.7 & 1.0 & 1.2 & 0.9 & 0.9 & 0.9 & 0.9 \\
\hline \multicolumn{11}{|c|}{ Smoking habits 2006} \\
\hline Non-smokers & 3538 & 75.8 & 74.0 & 56.8 & 45.6 & 48.1 & 55.2 & 61.2 & 58.1 & 59.1 \\
\hline Ex-smokers & 1372 & 7.8 & 13.3 & 20.5 & 30.1 & 34.0 & 22.0 & 23.1 & 22.5 & 21.8 \\
\hline Smokers & 1178 & 16.4 & 12.7 & 22.7 & 24.3 & 17.9 & 22.8 & 15.7 & 19.3 & 19.1 \\
\hline$<5$ cig/day & 279 & 7.2 & 3.6 & 4.7 & 4.6 & 3.4 & 4.8 & 4.4 & 4.6 & 4.6 \\
\hline 5-14 cig/day & 609 & 6.8 & 6.1 & 11.5 & 13.8 & 9.6 & 13.2 & 6.6 & 10.0 & 9.8 \\
\hline$>14$ cig/day & 237 & 1.7 & 2.5 & 5.5 & 4.9 & 3.8 & 3.9 & 3.9 & 3.9 & 3.8 \\
\hline Missing data & 53 & 0.6 & 0.6 & 0.9 & 0.9 & 1.2 & 0.8 & 0.9 & 0.9 & 0.9 \\
\hline P-value* & & 0.003 & $<0.001$ & $<0.001$ & $<0.001$ & 0.002 & $<0.001$ & $<0.001$ & $<0.001$ & \\
\hline
\end{tabular}

$\mathrm{All}^{\mathrm{\alpha}}=$ Standardized to the age and gender distribution in Norrbotten each year.

${ }^{*}$ Chi-square test of difference in prevalence of smoking habits in terms of non-smokers, ex-smokers and smokers between surveys.

Ca $1 \%$ lacks data of smoking habits each year.

Also among subjects with physician-diagnosed asthma, the proportion reporting symptoms common in asthma decreased significantly from 1996 to 2006; any wheeze from 72.1 to $63.7 \%(\mathrm{p}=0.001)$, recurrent wheeze from 62.2 to $51.0 \%(\mathrm{p}<0.001)$, asthmatic wheeze from 42.9 to $32.9 \%(\mathrm{p}<0.001)$ and use of asthma medication from 80.2 to $75.5 \%(\mathrm{p}=0.036)$.

The prevalence of physician-diagnosed asthma decreased with increasing age in both surveys (except in the age group 60-69 years in 1996) (Figure 2), while the prevalence of chronic productive cough and recurrent wheeze increased with increasing age. The prevalence of most symptoms and use of asthma medication was higher among women than men in both surveys (Table 3).

Respiratory symptoms and asthma in relation to smoking Among non-smokers, ex-smokers, as well as among smokers, the prevalence of most asthma variables increased significantly from 1996 to 2006. The prevalence of bronchitis variables did not differ between 1996 and 2006 among smokers or ex-smokers, but decreased significantly among non-smokers. The prevalence of wheeze variables did not differ significantly between the surveys when stratified by smoking habits, except for an increase in any wheeze among smokers (Table 4).
From 1996 to 2006, the proportion of smokers decreased also among symptomatics; i.e. from 37.7 to $28.8 \%(\mathrm{p}=0.005)$ among subjects with chronic productive cough, from 37.9 to $30.6 \%$ ( $\mathrm{p}<0.001$ ) among subjects with sputum production, from 34.6 to $31.0 \%(\mathrm{p}=0.151$ ) among subjects with longstanding cough, from 43.8 to $34.1 \%(\mathrm{p}<0.001)$ among subjects with recurrent wheeze, from 37.5 to $27.7 \%(\mathrm{p}=0.001)$ among subjects with asthmatic wheeze and from 24.7 to $19.9 \%(p=0.035)$ among subjects with physician-diagnosed asthma.

All respiratory symptoms were significantly and strongly related to smoking in both surveys. For the asthma variables, the highest prevalence was found among ex-smokers (Table 4). Smoking and ex-smoking were consistently associated with recurrent wheeze in both surveys (Table 5). The OR:s increased with increased cigarette consumption, and the highest OR:s $(>3)$ were found for recurrent wheeze and chronic productive cough among those who smoked $>14$ cigarettes/ day. Physician-diagnosed asthma was significantly associated with ex-smoking with an OR of 1.33 in 1996 and 1.41 in 2006.

\section{Population attributable risk (PAR) of smoking}

The PAR of smoking decreased slightly from 1996 to 2006 for all symptoms but longstanding cough. PAR was 
Table 3 Prevalence (\%) of respiratory symptoms and asthma by study year, age group and sex

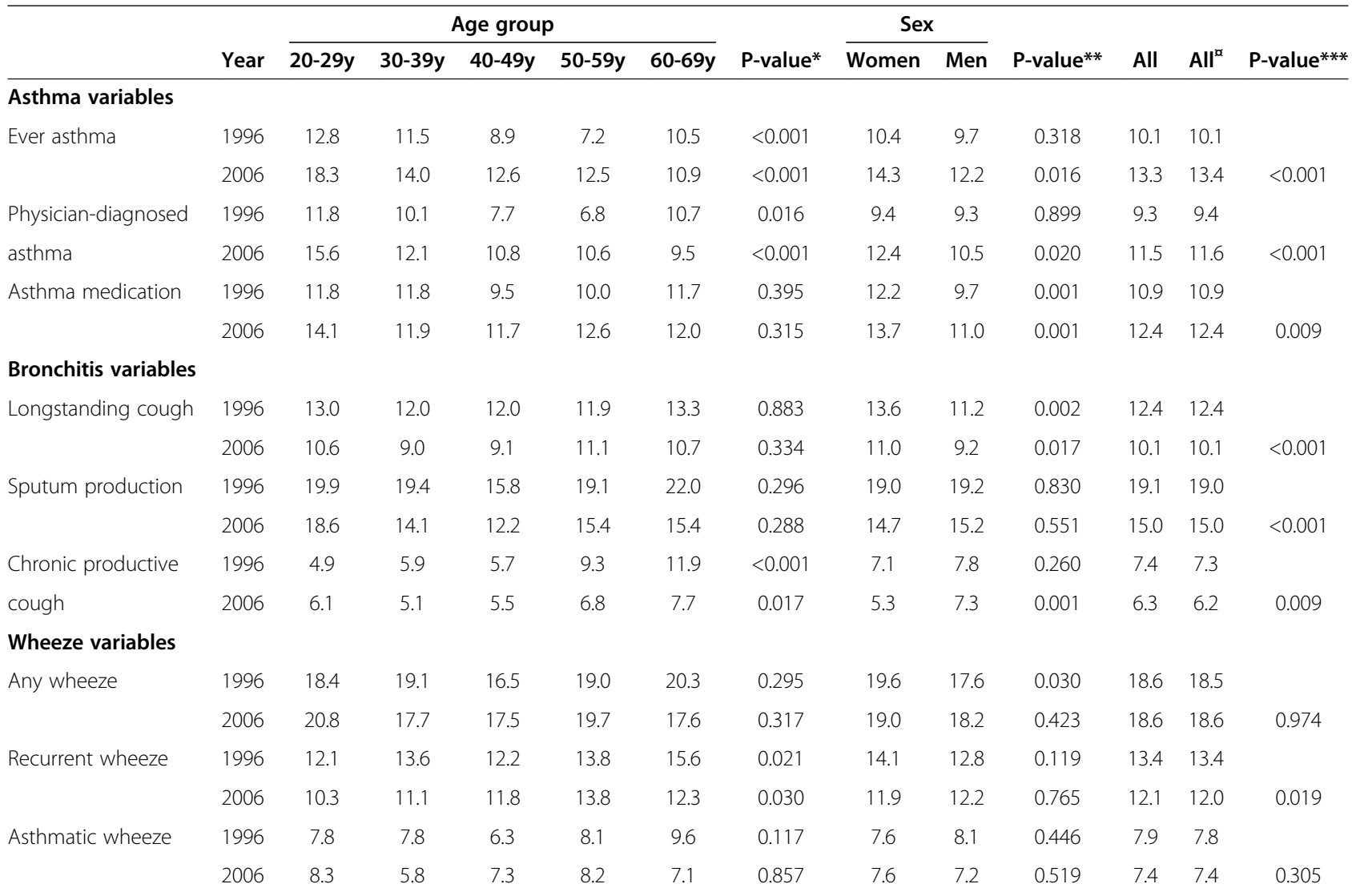

$\mathrm{All}^{\mathrm{a}}=$ Standardized to the age and gender distribution in Norrbotten each year.

*Test for trend by age group.

${ }^{* *}$ Chi-square test of difference in prevalence by sex.

${ }^{* * *}$ Chi-square test of difference in prevalence by year of study (among All).

highest for recurrent wheeze both years $(22.6 \%$ in 1996 , $18.3 \%$ in 2006), and ranged from $9.8 \%$ to $14.1 \%$ for the bronchitis symptoms. PAR of smoking was not significant for physician-diagnosed asthma (Figure 3). In both surveys, adjusted PAR tended to be higher than PAR. Adjusted PAR was highest for recurrent wheeze (25.5\% in $1996,20.6 \%$ in 2006), and ranged from $10.9 \%$ to $18.0 \%$ for the bronchitis symptoms.

\section{Discussion}

The main result of our study is the decrease in prevalence of most respiratory symptoms, particularly symptoms of bronchitis, from 1996 to 2006. This decrease parallels a $30 \%$ decrease in smoking prevalence, a decrease which was significant in all age groups, in both sexes, and in the proportion of smokers consuming $>14$ cigarettes/day. All respiratory symptoms were associated with smoking, and the proportion of respiratory symptoms attributed to smoking (PAR of smoking) varied from 10 to $25 \%$. The decrease in smoking prevalence was greater than the decrease in prevalence of symptoms, and a tendency of a decrease in PAR of smoking from 1996 to 2006 was observed for most respiratory symptoms. In contrast to respiratory symptoms, the prevalence of physician-diagnosed asthma increased and asthma was not consistently associated with smoking.

It is of great importance for preventive decisions to identify effects of changes in smoking habits on respiratory health in the population. In 2005, legislation was implemented in Sweden to reduce smoking in restaurants, which probably contributed to the decrease in smoking. More women than men smoked already in 1996, and the decrease in smoking prevalence was more pronounced among men compared to women. Thus, the gender difference in smoking prevalence increased. Worryingly, a recent study indicates an increase in prevalence of smoking and symptoms of bronchitis among teen-age girls in Sweden [31]. It is of great importance to establish a decrease in cigarette consumption also among women; in particular since women are more susceptible to cigarette smoke than men [32].

Few studies have reported PAR of smoking for respiratory symptoms and asthma. Our results imply that if smoking had been eliminated, $10-25 \%$ of the symptom prevalence in the population would have been 


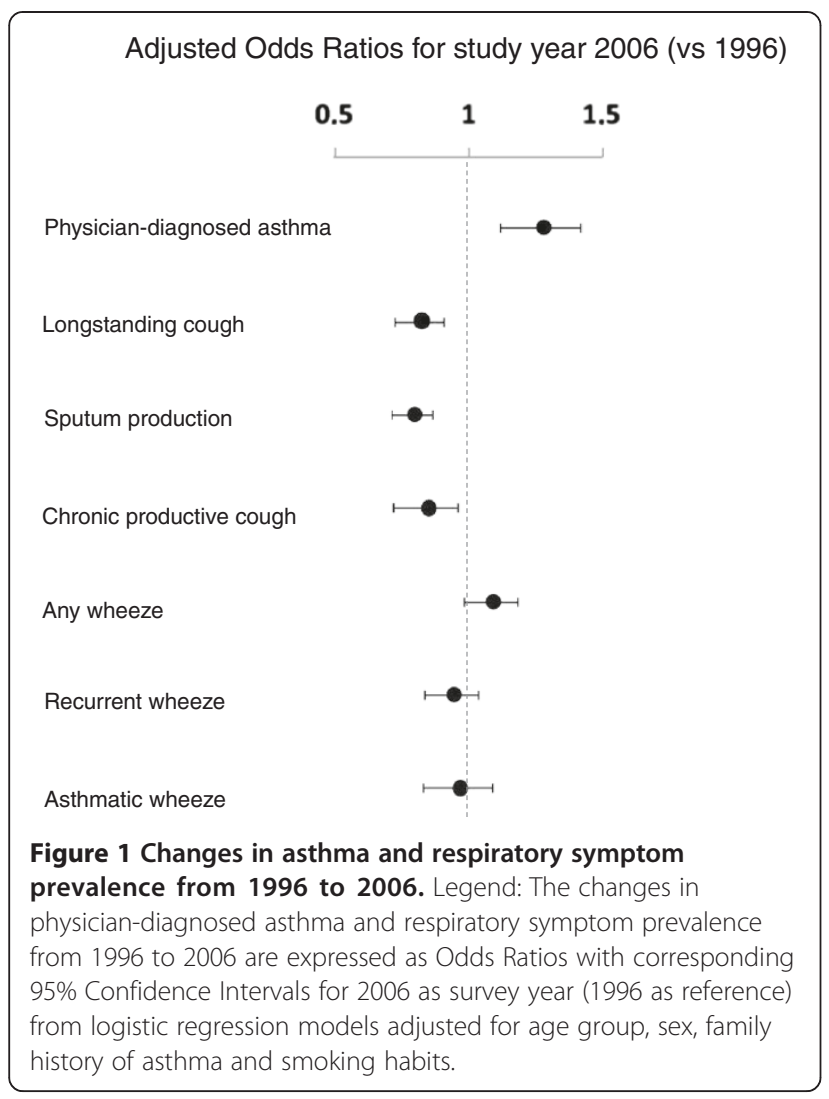

eliminated. A study comparing the Swedish part of the Global Allergy and Asthma European Network (GA2LEN) study performed in 2008 with the Swedish part of the European Community Respiratory Health Survey (ECHRS) from 1990 [5] also found a decrease in the prevalence of smoking, and a decrease in PAR of smoking for any wheeze. However, the methods for estimating PAR differed somewhat between the present study and the cited study.

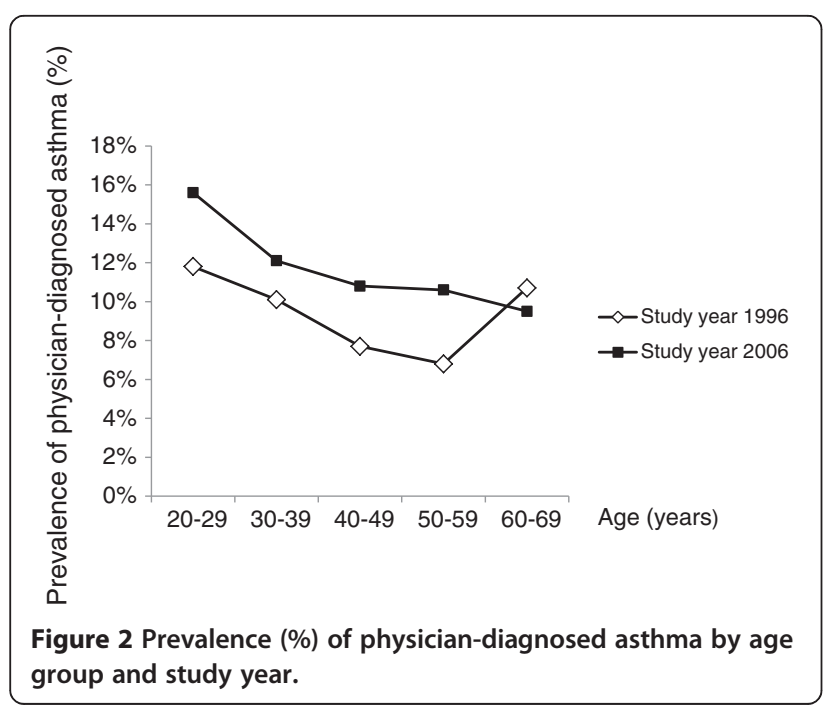

Comparisons of prevalence estimates between studies are difficult, since populations, questionnaires, and classification of symptoms and diseases often differ. One major advantage of our study is the use of identical methods in both surveys. The same methods as in our study were used in Helsinki, Finland, and that study also found a decrease in symptoms of bronchitis parallel to a decrease in smoking prevalence from 1996 to 2006 [21]. In west Sweden, a decrease was seen in the prevalence of most respiratory symptoms from 1990 to 2008 parallel to a $50 \%$ decrease in smoking prevalence [6]. In contrast to our results and the studies cited above, a study in Stockholm using identical methods found the prevalence of symptoms to be more or less level from 1996 to 2006 , despite a decrease in smoking prevalence by $43 \%$ [22].

The decrease in the prevalence of bronchitis symptoms is probably mainly a result of the decrease in smoking prevalence, but also of some other factor since we found a decrease among non-smokers. The decrease among non-smokers could be related to a reduction of environmental tobacco smoke (ETS), which followed the stricter Swedish smoking legislation. The increase in use of asthma medication, which can be prescribed also for bronchitis symptoms, may also contribute to a decrease in symptoms.

Wheeze is a common symptom both in asthma and bronchitis and is strongly related to smoking $[6,22,25]$. In contrast to bronchitis symptoms, the prevalence of any wheeze and asthmatic wheeze remained at a similar level in 2006 compared to 1996, also stratified by smoking habits, while recurrent wheeze decreased slightly but significantly. Since PAR of smoking was largest for recurrent wheeze, with smoking explaining about one fifth of the symptom prevalence, a decrease in the prevalence of recurrent wheeze was expected due to the decrease in smoking prevalence. Actually, a pronounced decrease in the prevalence of all wheeze symptoms was expected due to the decrease in smoking prevalence. One hypothesis that would explain the lack of an overall decrease in wheeze symptoms is that a parallel increase in asthma prevalence levels the prevalence of wheeze. Smoking has some anti-inflammatory effects and may be inversely related to allergic sensitisation [33,34]. Regarding asthma however, there is no data indicating a similar effect of smoking. Instead several studies suggest no effect or an increased risk of smoking on the incidence of asthma among adults [8-11]. Further, parental smoking increases the risk for childhood asthma [35,36]. Thus, it is not likely that the increase in asthma is related to the decrease in smoking.

Compared to similar studies from other countries $[13,14,37]$ as well as in other Swedish studies using the same questionnaire as in our study $[6,21,28]$, a higher 
Table 4 Prevalence (\%) of respiratory symptoms and asthma by study year and smoking habits

\begin{tabular}{|c|c|c|c|c|c|c|c|c|}
\hline & \multirow[b]{2}{*}{ Year } & \multicolumn{2}{|c|}{ Non-smokers } & \multicolumn{2}{|c|}{ Ex-smokers } & \multicolumn{2}{|c|}{ Smokers } & \multirow[b]{2}{*}{$\begin{array}{c}\text { Diff by smoking } \\
\text { P-value }\end{array}$} \\
\hline & & $\%$ & $\begin{array}{c}\text { Diff by year } \\
\text { P-value }\end{array}$ & $\%$ & $\begin{array}{c}\text { Diff by year } \\
\text { P-value }\end{array}$ & $\%$ & $\begin{array}{c}\text { Diff by year } \\
\text { P-value }\end{array}$ & \\
\hline \multicolumn{9}{|l|}{ Asthma variables } \\
\hline \multirow[t]{2}{*}{ Ever asthma } & 1996 & 9.9 & & 11.1 & & 9.4 & & 0.257 \\
\hline & 2006 & 12.3 & 0.002 & 15.0 & 0.002 & 14.3 & $<0.001$ & 0.021 \\
\hline Physician-diagnosed & 1996 & 9.0 & & 11.0 & & 8.3 & & 0.023 \\
\hline asthma & 2006 & 10.6 & 0.023 & 12.0 & 0.053 & 11.8 & 0.001 & 0.026 \\
\hline \multirow[t]{2}{*}{ Asthma medication } & 1996 & 10.7 & & 12.0 & & 10.5 & & 0.322 \\
\hline & 2006 & 11.2 & 0.453 & 14.8 & 0.026 & 12.7 & 0.058 & 0.003 \\
\hline \multicolumn{9}{|l|}{ Bronchitis variables } \\
\hline \multirow[t]{2}{*}{ Longstanding cough } & 1996 & 11.7 & & 10.0 & & 15.6 & & $<0.001$ \\
\hline & 2006 & 7.8 & $<0.001$ & 10.8 & 0.485 & 16.1 & 0.712 & $<0.001$ \\
\hline \multirow[t]{2}{*}{ Sputum production } & 1996 & 16.1 & & 16.9 & & 26.3 & & $<0.001$ \\
\hline & 2006 & 12.1 & $<0.001$ & 14.9 & 0.157 & 23.7 & 0.098 & $<0.001$ \\
\hline \multirow[t]{2}{*}{ Chronic productive cough } & 1996 & 6.4 & & 6.4 & & 10.2 & & $<0.001$ \\
\hline & 2006 & 5.1 & 0.027 & 6.6 & 0.879 & 9.3 & 0.436 & $<0.001$ \\
\hline \multicolumn{9}{|l|}{ Wheeze variables } \\
\hline \multirow[t]{2}{*}{ Any wheeze } & 1996 & 14.4 & & 17.0 & & 27.6 & & $<0.001$ \\
\hline & 2006 & 14.2 & 0.836 & 19.0 & 0.175 & 31.2 & 0.029 & $<0.001$ \\
\hline \multirow[t]{2}{*}{ Recurrent wheeze } & 1996 & 9.5 & & 12.4 & & 21.4 & & $<0.001$ \\
\hline & 2006 & 8.6 & 0.156 & 13.0 & 0.668 & 21.1 & 0.848 & $<0.001$ \\
\hline \multirow[t]{2}{*}{ Asthmatic wheeze } & 1996 & 6.1 & & 8.5 & & 10.8 & & $<0.001$ \\
\hline & 2006 & 5.7 & 0.469 & 9.0 & 0.591 & 10.5 & 0.834 & $<0.001$ \\
\hline
\end{tabular}

prevalence of asthma was found in Norrbotten. This finding confirms previous indications of a north-south gradient in asthma prevalence in Sweden [38,39]. The prevalence of physician-diagnosed asthma increased from 1996 to 2006, also when stratified by smoking. The highest prevalence of asthma was found among ex-smokers, a result confirming other cross-sectional studies $[6,12]$. It is known that diagnosis of COPD significantly impacts smokers to quit smoking [40] and therefore it could be suggested that smokers who get an asthma diagnosis also are likely to quit smoking, as several studies have found an association between current smoking and incident asthma $[8,10,11]$. The prevalence of physiciandiagnosed asthma decreased by age in both surveys, in line with results from other studies [6,22]. In 1996 however, in contrast to 2006, there was a higher prevalence of asthma in the oldest age group (60-69 years) compared to those aged $30-59$ years. This result might reflect misclassification of COPD as asthma among the elderly in 1996.

Does the estimated increase in the prevalence of asthma reflect a "true" increase in asthma? The proportion reporting symptoms common in asthma decreased significantly from 1996 to 2006 among subjects with physician-diagnosed asthma. This decrease occurred despite the fact that the proportion of subjects using asthma medicines also decreased significantly among the asthmatics. These data suggest an increased awareness of asthma in the society, improved recognition of asthma in primary care and an increasing diagnostic activity, in particular of mild asthma, which probably have contributed to the observed increase in physician-diagnosed asthma; a result in line with studies in other areas $[6,21,22]$. On the other hand, the lack of decrease in asthmatic wheeze and any wheeze despite the major decrease in smoking prevalence may indicate a true increase in asthma in Northern Sweden. Also, both asthma and use of asthma medication increased most in the youngest age group, which imply a true increase of asthma since misclassification of asthma as e.g. COPD is unlikely among young subjects. One might argue that the observed increase in asthma could be due to both a true increase in asthma as well as an increased diagnostic activity, which would be a result in line with studies from other countries [41]. This hypothesis requires further studies including clinical examinations. In our study, the majority of subjects with physician-diagnosed asthma used asthma medicines in both surveys, although 
Table 5 Risk factor analysis: Odds Ratios with 95\% Confidence Intervals from logistic regression models

\begin{tabular}{|c|c|c|c|c|c|c|c|c|c|c|c|c|c|}
\hline & & \multicolumn{12}{|c|}{ Dependent variables } \\
\hline & & \multicolumn{4}{|c|}{ Chronic productive cough } & \multicolumn{4}{|c|}{ Physician-diagnosed asthma } & \multicolumn{4}{|c|}{ Recurrent wheeze } \\
\hline & & \multicolumn{2}{|c|}{$\begin{array}{l}\text { Study year } \\
1996\end{array}$} & \multicolumn{2}{|c|}{$\begin{array}{l}\text { Study year } \\
2006\end{array}$} & \multicolumn{2}{|c|}{$\begin{array}{c}\text { Study year } \\
1996\end{array}$} & \multicolumn{2}{|c|}{$\begin{array}{l}\text { Study year } \\
2006\end{array}$} & \multicolumn{2}{|c|}{$\begin{array}{c}\text { Study year } \\
1996\end{array}$} & \multicolumn{2}{|c|}{$\begin{array}{l}\text { Study year } \\
2006\end{array}$} \\
\hline \multicolumn{2}{|c|}{ Independent variables } & OR & $95 \% \mathrm{Cl}$ & OR & $95 \% \mathrm{Cl}$ & OR & $95 \% \mathrm{Cl}$ & OR & $95 \% \mathrm{Cl}$ & OR & $95 \% \mathrm{Cl}$ & OR & $95 \% \mathrm{Cl}$ \\
\hline \multirow[t]{5}{*}{ Age } & 20-29 years & 1 & & 1 & & 1 & & 1 & & 1 & & 1 & \\
\hline & 30-39 years & 1.14 & $(0.82-1.60)$ & 0.87 & $(0.59-1.28)$ & 0.82 & $(0.65-1.05)$ & 0.78 & $(0.60-1.01)$ & 1.04 & $(0.83-1.31)$ & 1.18 & $(0.88-1.58)$ \\
\hline & $40-49$ years & 1.01 & $(0.73-1.42)$ & 0.85 & $(0.59-1.22)$ & 0.60 & $(0.46-0.77)$ & 0.64 & $(0.50-0.83)$ & 0.82 & $(0.65-1.04)$ & 1.07 & $(0.81-1.41)$ \\
\hline & $50-59$ years & 1.80 & $(1.32-2.47)$ & 1.07 & $(0.76-1.52)$ & 0.55 & $(0.42-0.72)$ & 0.62 & $(0.48-0.80)$ & 1.03 & $(0.81-1.29)$ & 1.25 & $(0.96-1.64)$ \\
\hline & $60-69$ years & 2.59 & $(1.90-3.53)$ & 1.35 & $(0.95-1.92)$ & 0.89 & $(0.69-1.15)$ & 0.60 & $(0.46-0.79)$ & 1.31 & $(1.04-1.65)$ & 1.23 & $(0.93-1.63)$ \\
\hline \multirow[t]{2}{*}{ Sex } & Female & 1 & & 1 & & 1 & & 1 & & 1 & & 1 & \\
\hline & Male & 1.17 & $(0.98-1.41)$ & 1.55 & $(1.25-1.92)$ & 1.05 & $(0.89-1.24)$ & 0.90 & $(0.77-1.06)$ & 0.98 & $(0.85-1.13)$ & 1.19 & $(1.01-1.39)$ \\
\hline \multirow{2}{*}{$\begin{array}{l}\text { Family history } \\
\text { of asthma }\end{array}$} & No/Don't know & 1 & & 1 & & 1 & & 1 & & 1 & & 1 & \\
\hline & Yes & 1.81 & $(1.49-2.21)$ & 2.37 & $(1.91-2.95)$ & 3.26 & $(2.76-3.85)$ & 3.39 & $(2.88-4.00)$ & 2.41 & $(2.07-2.79)$ & 2.71 & $(2.30-3.20)$ \\
\hline \multirow[t]{5}{*}{ Smoking habits } & Non-smokers & 1 & & 1 & & 1 & & 1 & & 1 & & 1 & \\
\hline & Ex-smokers & 0.89 & $(0.69-1.14)$ & 1.17 & $(0.89-1.54)$ & 1.33 & $(1.09-1.64)$ & 1.41 & $(1.15-1.72)$ & 1.34 & $(1.10-1.62)$ & 1.50 & $(1.22-1.85)$ \\
\hline & $<5$ cig/day & 0.60 & $(0.35-1.02)$ & 1.41 & $(0.87-2.28)$ & 1.01 & $(0.70-1.46)$ & 1.09 & $(0.74-1.61)$ & 1.70 & $(1.26-2.30)$ & 2.18 & $(1.55-3.06)$ \\
\hline & 5-14 cig/day & 1.43 & $(1.09-1.86)$ & 1.61 & $(1.14-2.27)$ & 0.85 & $(0.65-1.12)$ & 1.33 & $(1.01-1.74)$ & 2.61 & $(2.14-3.17)$ & 3.09 & $(2.45-3.91)$ \\
\hline & $>14$ cig/day & 3.07 & $(2.35-4.02)$ & 3.31 & $(2.23-4.91)$ & 0.95 & $(0.67-1.34)$ & 0.68 & $(0.41-1.14)$ & 3.49 & $(2.77-4.40)$ & 3.32 & $(2.39-4.63)$ \\
\hline
\end{tabular}

Statistically significant Odds Ratios (OR) with corresponding $95 \%$ Confidence Intervals (Cl) are bolded.

somewhat less so in 2006 compared to 1996. In a study from Australia the authors argue that improved guidelines on how to implement asthma treatment are required [42], but as we cannot provide detailed information about use of inhaled corticosteroids we cannot evaluate if the adherence to maintenance treatment is appropriate.

The validity and reliability of the present study was high due to the population-based samples, the high participation rates in both surveys and the use of a validated

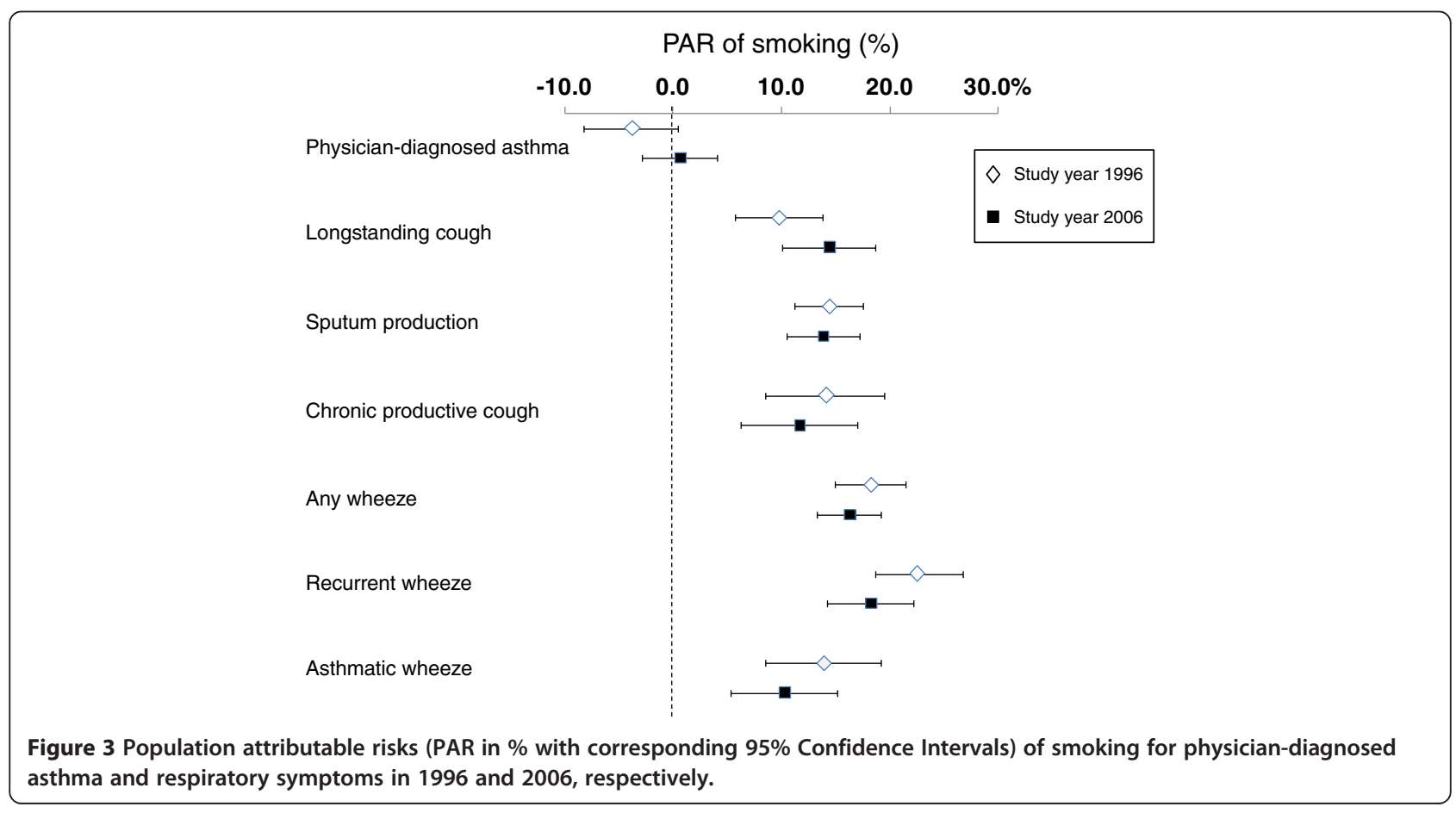


questionnaire. The somewhat lower participation rate in 2006 compared to 1996 could possibly lead to a slight overestimation of symptom prevalence in 2006 [43]. An overestimation in 2006 would not alter the findings of decreased prevalence in symptoms, but could possibly affect the observed increase in asthma prevalence. However, the close to identical prevalence estimates after adjustment to the age and gender distribution in Norrbotten each year verify the representativeness of the study sample. A weakness is the lack of clinical data when discussing asthma, and measures of cotinine for validating data about smoking. Further, data of exposure to ETS, body weight, gastro-oesophageal reflux, obstructive sleep apnoea and occupational dust exposure would have been valuable, since the presence of these factors may have changed between surveys, which in turn could have contributed to a change in both respiratory symptom and asthma prevalence. The cross-sectional study design weakens the discussion of causality. However, the strong and consistent association between smoking and respiratory symptoms in both surveys as well as the decrease of both smoking and bronchitis symptoms imply an improvement in respiratory health in the population at least partly due to the decrease in smoking.

\section{Conclusions}

In conclusion, we found that respiratory symptoms, in particular bronchitis symptoms, decreased parallel to a decrease in smoking over a 10-year period from 1996 to 2006. In contrast, the prevalence of physician-diagnosed asthma increased during the same period. The hypothesis that the observed increase in asthma reflects a "true" increase in asthma prevalence has to be confirmed by clinical studies. Additionally, up to one fourth of the respiratory symptom prevalence in the population was attributable to smoking.

\section{Competing interests}

None of the authors have any competing interests to declare.

\section{Authors' contributions}

HB carried out all data management and statistical analyses, interpreted data, drafted and finalized the manuscript. LH helped to draft the manuscript and interpret data. S-A J revised the manuscript. AL revised the manuscript and interpreted data. BL and ER designed and coordinated the study, revised the manuscript and contributed with important input to discussion. ER conceived the study and participated in the data collection process as well as supervised the analyses. All authors read and approved the final manuscript.

\section{Acknowledgements}

We would like to acknowledge the OLIN staff for collecting the data. Financial support was received from The Swedish Heart \& Lung Foundation, The Swedish Research Council, Umeå University, the Swedish Asthma-Allergy Foundation, Norrbotten County Council and Visare Norr.

\section{Author details}

${ }^{1}$ The OLIN Studies, Department of Research and Development, Norrbotten County Council, Luleå, Sweden. ${ }^{2}$ Division for Occupational and Environmental Medicine, Department of Public Health and Clinical Medicine, Umeå University, Umeå, Sweden. ${ }^{3}$ Division for Respiratory Medicine and Allergy, Department of Public Health and Clinical Medicine, Umeå University,
Umeå, Sweden. ${ }^{4}$ Krefting Research Centre/Department of Internal Medicine, The Sahlgrenska Academy, University of Gothenburg, Gothenburg, Sweden.

Received: 1 August 2013 Accepted: 17 December 2013

Published: 2 January 2014

\section{References}

1. Ezzati M, Hoorn SV, Rodgers A, Lopez AD, Mathers CD, Murray CJ, et al Estimates of global and regional potential health gains from reducing multiple major risk factors. Lancet 2003, 362(9380):271-280.

2. Eriksen M, Mackay J, Ross H: The Tobacco Atlas by the World Lung Foundation \& American Cancer Society. Available at: http://www. tobaccoatlas.org. Accessed 04/03, 2013.

3. Jarvis A: A study on liability and the health costs of smoking. DG SANCO (2008/C6/046) UPDATED FINAL REPORT April 2012. 2013. Available at: http://ec.europa.eu/health/tobacco/products/revision/index_en.htm. Accessed 27/12, 2013.

4. Slama K: Global perspective on tobacco control. Part I. The global state of the tobacco epidemic. Int J Tuberc Lung Dis 2008, 12(1):3-7.

5. Bjerg A, Ekerljung L, Middelveld R, Dahlen SE, Forsberg B, Franklin K, et al: Increased prevalence of symptoms of rhinitis but not of asthma between 1990 and 2008 in Swedish adults: comparisons of the ECRHS and GA(2)LEN surveys. PLoS One 2011, 6(2):e16082.

6. Lotvall J, Ekerljung L, Ronmark EP, Wennergren G, Linden A, Ronmark E, et al: West Sweden Asthma Study: prevalence trends over the last 18 years argues no recent increase in asthma. Respir Res 2009, 10:94

7. Lindberg A, Eriksson B, Larsson LG, Ronmark E, Sandstrom T, Lundback B: Seven-year cumulative incidence of COPD in an age-stratified general population sample. Chest 2006, 129(4):879-885.

8. Larsson L: Incidence of asthma in Swedish teenagers: relation to sex and smoking habits. Thorax 1995, 50(3):260-264.

9. Ronmark E, Lundback B, Jonsson E, Jonsson AC, Lindstrom M, Sandstrom T: Incidence of asthma in adults-report from the obstructive lung disease in northern Sweden study. Allergy 1997, 52(11):1071-1078.

10. Piipari R, Jaakkola JJ, Jaakkola N, Jaakkola MS: Smoking and asthma in adults. Eur Respir J 2004, 24(5):734-739.

11. Eagan TM, Bakke PS, Eide GE, Gulsvik A: Incidence of asthma and respiratory symptoms by sex, age and smoking in a community study. Eur Respir J 2002, 19(4):599-605.

12. Viegi G, Pedreschi M, Baldacci S, Chiaffi L, Pistelli F, Modena P, et al: Prevalence rates of respiratory symptoms and diseases in general population samples of North and Central Italy. Int J Tuberc Lung Dis 1999, 3(11):1034-1042.

13. Arif AA, Delclos GL, Lee ES, Tortolero SR, Whitehead LW: Prevalence and risk factors of asthma and wheezing among US adults: an analysis of the NHANES III data. Eur Respir J 2003, 21(5):827-833.

14. Browatzki A, Ulrik CS, Lange P: Prevalence and severity of self-reported asthma in young adults, 1976-2004. Eur Respir J 2009, 34(5):1046-1051.

15. Campbell MJ, Cogman GR, Holgate ST, Johnston SL: Age specific trends in asthma mortality in England and Wales, 1983-95: results of an observational study. BMJ 1997, 314(7092):1439-1441.

16. Jansson SA, Andersson F, Borg S, Ericsson A, Jonsson E, Lundback B: Costs of COPD in Sweden according to disease severity. Chest 2002, 122(6):1994-2002.

17. Jansson SA, Ronmark E, Forsberg B, Lofgren C, Lindberg A, Lundback B: The economic consequences of asthma among adults in Sweden. Respir Med 2007, 101(11):2263-2270.

18. de Marco R, Cappa V, Accordini S, Rava M, Antonicelli L, Bortolami O, et al: Trends in the prevalence of asthma and allergic rhinitis in Italy between 1991 and 2010. Eur Respir J 2012, 39(4):883-892.

19. Hansen EF, Rappeport $Y$, Vestbo J, Lange P: Increase in prevalence and severity of asthma in young adults in Copenhagen. Thorax 2000, 55(10):833-836.

20. Upton MN, McConnachie A, McSharry C, Hart CL, Smith GD, Gillis CR, et al: Intergenerational 20 year trends in the prevalence of asthma and hay fever in adults: the Midspan family study surveys of parents and offspring. BMJ 2000, 321(7253):88-92.

21. Kainu A, Pallasaho P, Piirila P, Lindqvist A, Sovijarvi A, Pietinalho A: Increase in prevalence of physician-diagnosed asthma in Helsinki during the Finnish Asthma Programme: improved recognition of asthma in primary care? A cross-sectional cohort study. Prim Care Respir J 2013, 22(1):64-71. 
22. Ekerljung L, Andersson A, Sundblad BM, Ronmark E, Larsson K, Ahlstedt S, et al: Has the increase in the prevalence of asthma and respiratory symptoms reached a plateau in Stockholm, Sweden? Int I Tuberc Lung Dis 2010, 14(6):764-771.

23. Braun-Fahrlander C, Gassner M, Grize L, Takken-Sahli K, Neu U, Stricker T, et al: No further increase in asthma, hay fever and atopic sensitisation in adolescents living in Switzerland. Eur Respir J 2004, 23(3):407-413.

24. World Health Organisation W. Burden of COPD; 2013. Available at: http:// www.who.int/respiratory/copd/burden/en/. Accessed 04/05, 2013.

25. Lundback B, Nystrom L, Rosenhall L, Stjernberg N: Obstructive lung disease in northern Sweden: respiratory symptoms assessed in a postal survey. Eur Respir J 1991, 4(3):257-266.

26. Pallasaho P, Lundback B, Meren M, Kiviloog J, Loit HM, Larsson K, et al: Prevalence and risk factors for asthma and chronic bronchitis in the capitals Helsinki, Stockholm, and Tallinn. Respir Med 2002, 96(10):759-769.

27. Lindstrom M, Kotaniemi J, Jonsson E, Lundback B: Smoking, respiratory symptoms, and diseases: a comparative study between northern Sweden and northern Finland: report from the FinEsS study. Chest 2001, 119(3):852-861.

28. Montnemery P, Adelroth E, Heuman K, Johannisson A, Johansson SA, Lindholm $\mathrm{LH}$, et al: Prevalence of obstructive lung diseases and respiratory symptoms in southern Sweden. Respir Med 1998, 92(12):1337-1345.

29. Leung HM, Kupper LL: Comparisons of confidence intervals for attributable risk. Biometrics 1981, 37(2):293-302.

30. Rothman KJ, Greenland S, Lash TL: Modern Epidemiology. 3rd edition. Philadelphia, USA: Lippincott Williams \& Wilkins; 2008:296

31. Wennergren G, Ekerljung L, Bjerg A, Lotvall J, Lundback B: Alarmingly high prevalence of smoking and symptoms of bronchitis in young women in Sweden. Prim Care Res 2013. In press.

32. Langhammer A, Johnsen R, Gulsvik A, Holmen TL, Bjermer L: Sex differences in lung vulnerability to tobacco smoking. Eur Respir J 2003, 21(6):1017-1023

33. Eriksson J, Ekerljung L, Sundblad BM, Lotvall J, Toren K, Ronmark E, et al: Cigarette smoking is associated with high prevalence of chronic rhinitis and low prevalence of allergic rhinitis in men. Allergy 2013, 68(3):347-354.

34. Hancox RJ, Welch D, Poulton R, Taylor DR, McLachlan CR, Greene JM, et al: Cigarette smoking and allergic sensitization: a 32-year population-based cohort study. J Allergy Clin Immunol 2008, 121(1):38.e3-42.e3.

35. Ronmark E, Jonsson E, Platts-Mills T, Lundback B: Different pattern of risk factors for atopic and nonatopic asthma among children-report from the obstructive lung disease in Northern Sweden study. Allergy 1999, 54(9):926-935.

36. Strachan DP, Cook DG: Health effects of passive smoking. 6. Parental smoking and childhood asthma: longitudinal and case-control studies. Thorax 1998, 53(3):204-212.

37. Brogger J, Bakke P, Eide GE, Johansen B, Andersen A, Gulsvik A: Long-term changes in adult asthma prevalence. Eur Respir J 2003, 21(3):468-472.

38. Aberg N: Asthma and allergic rhinitis in Swedish conscripts. Clin Exp Allergy 1989, 19(1):59-63.

39. Lundback B: Epidemiology of rhinitis and asthma. Clin Exp Allergy 1998, 28(Suppl 2):3-10.

40. Stratelis $G$, Molstad $S$, Jakobsson P, Zetterstrom O: The impact of repeated spirometry and smoking cessation advice on smokers with mild COPD. Scand J Prim Health Care 2006, 24(3):133-139.

41. James AL, Knuiman MW, Divitini ML, Hui J, Hunter M, Palmer LJ, et al: Changes in the prevalence of asthma in adults since 1966: the Busselton health study. Eur Respir J 2010, 35(2):273-278.

42. Marks GB, Abramson MJ, Jenkins CR, Kenny P, Mellis CM, Ruffin RE, et al: Asthma management and outcomes in Australia: a nation-wide telephone interview survey. Respirology 2007, 12(2):212-219.

43. Ronmark EP, Ekerljung L, Lotvall J, Toren K, Ronmark E, Lundback B: Large scale questionnaire survey on respiratory health in Sweden: effects of late- and non-response. Respir Med 2009, 103(12):1807-1815.

doi:10.1186/1939-4551-7-1

Cite this article as: Backman et al:: Prevalence trends in respiratory symptoms and asthma in relation to smoking - two cross-sectional studies ten years apart among adults in northern Sweden. World Allergy Organization Journal 2014 7:1.

\section{Submit your next manuscript to BioMed Central and take full advantage of:}

- Convenient online submission

- Thorough peer review

- No space constraints or color figure charges

- Immediate publication on acceptance

- Inclusion in PubMed, CAS, Scopus and Google Scholar

- Research which is freely available for redistribution 